\title{
Preparation and Corrosion Inhibition of Single and Biphase Composite Coating Based on PEDOT in 0.1M NaOH
}

\author{
Shengjian Zhang, Min Li, Lijun Zhai \\ Department of Chemistry and Chemical Engineering, Taiyuan Institute of Technology, Taiyuan \\ 030008, P. R. China \\ *E-mail: zsj151732@163.com
}

doi: $10.20964 / 2019.05 .50$

Received: 28 January 2019 / Accepted: 11 March 2019 / Published: 10 April 2019

In this study, a compact poly(3,4-ethylenedioxythiophene) (PEDOT) film was deposited onto the surface of stainless steel (SS) to prepare PEDOT/SS by chronoamperometry. The porous polymer film is highly hydrophobic with a water contact angle of $\sim 140^{\circ}$ after the modification by fluorinate agents. Perfluorinated lubricant/PEDOT/SS (PFL/PEDOT/SS) was prepared by the infusion of perfluorinated lubricant. The corrosion inhibition properties of SS, PEDOT/SS and PFL/PEDOT/SS in acidic, neutral and alkaline solutions were investigated by electrochemical impedance spectroscopy and potentiodynamic polarization techniques. It is found that the PEDOT/SS matrix has a compact surface, and the biphase composites show significant corrosion inhibition effects on SS in alkaline solutions.

Keywords: Stainless steel; poly(3,4-ethylenedioxythiophene); slippery liquid-infused porous surfaces; perfluorinated lubricant; corrosion inhibition.

\section{FULL TEXT}

(C) 2019 The Authors. Published by ESG (www.electrochemsci.org). This article is an open access article distributed under the terms and conditions of the Creative Commons Attribution license (http://creativecommons.org/licenses/by/4.0/). 